\title{
Policing the Fluff: The Social Construction of Scientistic Selves in Otherkin Facebook Groups
}

\author{
DEVIN PROCTOR ${ }^{1}$ \\ THE GEORGE WASHINGTON UNIVERSITY
}

\begin{abstract}
The Otherkin are a group of people who identify as other-than-human. Primarily gathering in online spaces, they discuss and debate the origins and parameters of this identification and try to make sense of their extraordinary experiences. This article traces how the Otherkin deploy scientific facts and theories during this process, arriving at Otherkin science, a carefully curated compilation of abstract physics, psychology, metaphysics, and ancient belief that renders otherthan-human identification thinkable in a contemporary Western paradigm. Drawing on five years of ethnographic engagement with the Otherkin, this article examines this social knowledge construction through the processes of "questioning" and "grilling" on Otherkin Facebook groups. In continuously negotiating their own identities through scientific reasoning, they create what I am calling scientistic selves-frameworks of identification created by lay scientists whose adherence to specific scientific facts and theories is fundamental to their continued existence.
\end{abstract}

\section{Keywords}

STS; Facebook; Otherkin; lay science; ethnography

\section{Introduction}

A woman posts a comment to a Facebook group page in which she claims to have the ability to physically transform into a wolf. This is not a creative writing project, a werewolf fandom group, or any other imaginary enterprise. This Facebook group is part of an online community of Otherkin-people who sincerely identify, on some level, as other-than-human. The members of this particular group are therians-a subset of Otherkin who specifically identify as non-human animals. The claim the woman is making is called physical shifting, or "p-shifting," which is almost universally rejected by the Otherkin community at large as implausible and unscientific. As soon as the woman (hereafter OP1, for Original Poster number 1) makes this claim she is met with harsh rebuke, and Fei (an administrator of the group, and a wolf therian herself) responds with lupine bluntness:

. Devin Proctor, Email: dproctor@gwu.edu 
Fei: Um, wrong. Science has already proven p-shifting impossible. That is a fact. Now quit trying to lie, you're failing miserably and humiliating yourself. [... $]^{2}$

OP1: to say it is impossible is pretty narrow minded. I mean, how do you KNOW it's physically impossible? Just cuz that's what everyone else says.

Fei: $\quad$ No, it's cause that's what science says. Even if you were to somehow find a way to do it, all your organs would be crushed and liquefied. Try finishing high school hun. [...]

OP1: Ok... If Therianthropys can be rational and logical... then why can't P-Shifting?

Fei: $\quad$ Because p-shifting breaks the laws of science. Therianthropy doesn't. [...] We all know science. And this isn't a debate, this is us telling you facts. [...] We KNOW you're lying. Why are you even trying to convince us? You know you're lying too, and if you don't, you have a severe mental illness that needs to be treated immediately.

We face a paradox. On one hand, Fei argues that science does not support the prospect of transforming into an other-than-human being. In fact, she goes on to specify to OP1 that "it breaks several laws of physics and biology." And another member chides, "This is a group for discussing therianthropy. Not for lying or for wild fantasies." OP1 is mocked for falsehood and indulging in imagination. She is told she is young and immature (note Fei's offhand correction of "cuz" to "cause") and possibly mentally ill. On the other hand, Fei, along with the other members of the group, self-identify in a way that also runs counter to the foundations of contemporary Western science: they argue that they are not entirely human. Within them, in a very real experiential sense, is a non-human entity trapped inside a human body. An empirical scientific approach-which would hold that a person's "humanness" is a non-negotiable biological designation-would tend to classify this identity construct as misled, fanciful, and irrational. But, as Fei explicitly states above, "p-shifting breaks the laws of science. Therianthropy doesn't." So what "science" is it that Fei is referring to, which allows for one to be true, but not the other?

Compare the exchange above to a post in the same group from another woman (OP2) who claims to identify as a winged wolf:

OP2: Hey, pterolycus / arctic wolf kin here! Thanks for accepting my request.

Fei: $\quad$ Nice to meet you! What's a pterolycus?

OP2: A winged wolf, sorry probably should have specified that.

Fei: $\quad$ Ah ok. So how'd you figure out your kintypes?

OP2: Well, I have known I was some sort of canine for a long while, and finally recognized it as an arctic wolf. However, I would often get phantom limbs of wings... Last year some time I experienced an "M-shift" for the first time since elementary school. I found it really weird, instantly knowing it was not normal, so I looked it up thus starting my journey in the otherkin and therian community. I

2 The brackets $[\ldots]$ here indicate that I am omitting pieces of the conversation, mostly from other members having many overlapping discussions that confuse and detract from the topic at hand.

${ }^{3}$ Therianthropy is the condition of being a therian (or a therianthrope). 
don't know why, but for a while I thought the whole concept of identifying with something non-earthly was silly so I identified myself with purely an arctic wolf. Though lately, my phantom wings have been really strong. I have also always seen myself as a winged wolf when meditating, so finally I accepted the fact that I probably was a pterolycus.

[Fei and a few other group members mark OP2's comment with "likes"]

Unlike the derision and ultimate expulsion OP1 suffered, OP2 is met with acceptance and "likes" for what would seem like a similarly implausible claim: not only is she a wolf, but a winged wolf from Russian and Hungarian mythology. What could explain the stark difference in the group's attitude toward these two women and their wolf identifications? There is, of course, the obvious difference in tone-OP1 is confrontational, while OP2 is apologetic and forthcoming-but the meaningful distinction in this case has to do with evidence. OP2's explanations of "M-shifts" ( $\mathrm{M}$ for mental, as opposed to physical), phantom limbs, and meditative transcendence-along with a narrative of experimentation and rational skepticismalign with the particular type of scientific reasoning these groups practice. This is Otherkin science: a socially constructed combination of abstract physics, psychology, metaphysics, and ancient belief that renders other-than-human identification thinkable in a contemporary Western paradigm.

Otherkin science is conceived, constructed, deployed, and enforced by a lay group that, for all intents and purposes, appears to ignore central scientific tenets in their very self-definition. I argue here that, in fact, they take great pains to employ scientific knowledge in a rational and systematic way to explain their other-than-human identification. In doing so, they seek to mitigate the tension between their Cartesian epistemological frameworks of empirical science and their animistic ontological perception of other-than-humanness: the dissonance caused when what they know conflicts with what they experience. Exploring this tension through the Otherkin practices of "questioning" and "grilling," I further argue that contestations around scientific ways of knowing can reveal identity constructions that I call scientistic selves-frameworks of identification whose adherence to specific scientific facts and theories is fundamental to their continued existence. In my use of the term "scientistic" I do not mean to imply that these constructions use science in a degraded form or that they exhibit positivist zealotry, but rather that they are formed by nonprofessional scientists using the tools and formulations found in a popular understanding of scientific discourse. Daston and Galison describe the "scientific self" as driven by "epistemic virtue" (2007), compelling professional scientists to resist subjectivity through "the right kind of self-abnegation or self-restraint," to achieve a totally objective ideal (Stefano 2015, 93). A scientistic self, conversely, begins with an acceptance of the subjective experience or belief, and deploys scientific theories, facts, processes, and methods to help rationalize that experience. At stake personally for Otherkin scientistic selves in these practices is the ability to recognize and explain their own experiences in a way that renders them thinkable to others. While a fascinating case study on its own, looking at the Otherkin construction of science also marks some of the ways in which identities and scientific facts are contested in a larger sociopolitical context characterized by experiential "bubbles" and targeted misinformation; 
where facts have, in a sense, become fluid. Ultimately, the Otherkin demonstrate a struggle for the ownership of knowledge and authority outside of sanctioned expert positions, and how fragile-and necessarily policed—this ownership can be, even among supposedly like-minded allies.

In many ways, Otherkin science resembles the types of "fringe" science that reject mainstream expertise in favor of oppositional epistemological constructions (Collins, ReyesGalindo, and Bartlett 2016). This move to commandeer scientific language and knowledge from experts exemplifies a type of "epistemic democracy" that often privileges the non-expert (Lynch 2017; Collins, Evans, and Weinel 2017). Indeed, in some cases, "expertise appears as a repository of corrupt judgment designed to suppress promising alternatives to already bankrupt positions" (Fuller 2016b). While this theoretical and methodological tactic can do much to destabilize entrenched modes of knowledge production, recent debates have also considered how constructivist approaches might have contributed to the ascent of our current "post-truth" era (Fuller 2016a, 2016b; Sismondo 2017a, 2017b; Lynch 2017; Collins, Evans, and Weinel 2017). ${ }^{4}$ Much of this research took place during the 2016 Presidential election (and on Facebook, no less), when "alternative facts" and "fake news" became anti/post-truth buzzwords, so it reflects a particular moment in time; however, Otherkin negotiations with the "facts" of scientific knowledge predate the current political climate and come from a much more intimate source: their own bodies. While a mixture of expert and lay scientific knowledge about the body and the self is often deployed in the "ontological choreography" (Cussins 1996; Thompson 2007; Panofsky and Donovan 2017) of "making up human kinds" (Hacking 1995, 2006) and "self-fashioning" (Dumit 2003; Nelson 2008, 2016), STS has also examined processes of identity formation specifically utilizing fringe scientific frameworks. Creationist Christians, for instance, reference "creation science"-a combination of theology, geology, archaeology, and physics-to rationalize membership in a group whose beliefs would otherwise seem scientifically dubious (Toumey 1991; Harding 2001; Senter and Mackey 2017). How the Otherkin differ is that they do not apply scientific knowledge to explain an epistemological stance, but rather an ontological one: while Creationists begin with a belief in the inerrancy of biblical text, Otherkin begin with the experience of other-than-humanness within a human body.

Self-defining from earthly animals to mythological beasts, the Otherkin make up a group of at least 5,000 peoples who identify as other-than-human. While presenting to the world as

"STS scholars have recently debated whether the ascension of "post-truth" — evidenced by Brexit in Europe and the election of Donald Trump in the United States-can be blamed (in part) on the Science Wars within STS beginning in the 1970s (Fuller 2016a). Some claim that the democratization of scientific knowledge and the logic of symmetry framed science as "just another form of politics" and engendered a deep skepticism of experts in the populace (Collins, Evans, and Weinel 2017), resulting in a rise of "fringe science" (Collins, Reyes-Galindo, and Bartlett 2016). Sismondo (2017a, 2017b) argues that the comparison cannot be made; that "post-truth" - a position "in which bullshit is highly valued-misses a central and productive tension within STS... A twitter account alone does not make what we have been calling knowledge" (2017a).

"Otherkincommunity.net and Werelist.net, two of the Otherkin community's main websites, have 5,529, and 4,480 members, respectively, as of this writing. Some of my Otherkin interlocutors, however, estimate that there are over 10,000 in the online community. Taking into consideration the vast number people on the 
human, they experience these non-human aspects in urges, dreams, physical sensations, and memories. The entities represented in these forms can be native to the body, but can also come from external spatial and temporal sources: past lives, other dimensions, collective consciousness, and works of fiction. The label Otherkin is often used as an umbrella term, but the community splits into two subsets: "otherkin" (lowercase "o"), who identify as beings that do not exist on Earth" (elves, dragons, demons, angels, fae, etc); and the aforementioned "therians," who identify as animals that exist (or previously existed) on Earth such as wolves, sharks, saber-toothed cats, and otters (Lupa 2007). Generally, I will speak of Otherkin as an all-inclusive term, but the variation within the community is tremendous.' Despite manifold differences in specific identity claims, all Otherkin understand themselves to be deeply, unchangeably, other-than-human. Current scholarly work tends to view Otherkinity in one of three ways: as a religious belief system based in fictional works (Kirby 2008, 2013; O'Callaghan 2015; Davidsen 2013, 2016; Cusack 2016); as a neurological abnormality or pathological disorder (Gerbasi et al. 2008; ProbynRapsey 2011; Grivell, Clegg, and Roxburgh 2014); or as a community-based formation of selfknowledge infused with mythological and pop-cultural influences (Laycock 2012; Robertson 2012, 2013; Johnston 2013; Shane 2014). Having spent a great deal of time doing fieldwork with Otherkin, I have come to regard the phenomenon from more of an ontological position- that is, I understand their Otherkinity as deriving from an initial experience of other-than-humanness. As I argue elsewhere (Proctor 2018), this is fundamentally an animist experience, which would be taken as a matter of course in many societies around the world, but in (non-indigenous) North American and Western European contexts, is seen as deeply problematic, even pathological. There is no pre-existing (adult) niche for Otherkin identity in Western society, so after initially experiencing non-human otherness, Otherkin seek out answers and find the community, usually in the Internet. And through their interactions with the online Otherkin community, they come to understand and define their own Otherkinity, navigating the friction between their subjective experience and a larger epistemology of empiricist science and rationalism.

planet who do not have Internet access and (among the people who have access) those who do not speak English, the number could be much higher.

"In Pagan traditions-which many Otherkin follow-the fae, along with other non-human entities and deities, exist on earth and can materialize in concrete form. For my purposes, and in the official definitions put forward by the Otherkin community, I am defining "on Earth" in purely concrete, non-supernatural terms, limited to those presently observable or those with a fossil record.

"Self-identified "real vampires" - humans who gain sustenance either through others' energy or directly through their blood-are also often put under the Otherkin umbrella. Some Otherkin also have vampire kintypes, so there is a great deal of overlap. As this particular article deals mainly with the practices involved in non-human identification, vampires will not be discussed at length. For scholarly work on the real vampire community, see Laycock (2009, 2010), Johnston (2014), and Williams (2008, 2009).

s The obvious exception to this larger assertion is children at play. As I discuss elsewhere (Proctor 2018) children in the West are exposed to animistic characters and encouraged to role-play as other-than-human entities. In the context of this article I mean that there is no adult (e.g. serious) mode for identifying in otherthan-human ways in contemporary Western society. Further, the idea of animist identification as a parallel to children's play raises the specter of early anthropological cultural evolutionist narratives, framing indigenous societies as less advanced and childlike. 
This article continues a long tradition of examining the social constructedness of and coproductive relations inherent in/undergirding scientific knowledge (Berger and Luckmann 1966; Shapin and Schaffer 1985; Hacking 1999; Knorr-Cetina 1999; Jasanoff 2004). The construction is undertaken through many different processes, but this examination of Otherkin scientific construction focuses specifically on the practice of boundary work (Gieryn 1983) and the crafting of standardized packages (Fujimura 1992). Boundary work represents a more active and deliberate version of Mertonian demarcation (1973) in the sciences. In his study of scientists' discourse, Gieryn noted their "attribution of selected characteristics to the institution of science ... for purposes of constructing a social boundary that distinguishes some intellectual activities as "nonscience" $(1983,782)$. Similarly, the Otherkin engage in boundary work by framing those they deem illegitimate as both inauthentic and scientifically implausible, thus establishing themselves as the scientific authority. "When the goal is monopolization of professional authority and resources, boundary-work excludes rivals from within by defining them as outsiders with labels such as 'pseudo,' 'deviant,' or 'amateur'" (1983, 792). Or-in the case of the Otherkin-"fluff." Fujimura illustrates the construction of science through standardized packages as a compromise midway between two theoretical camps: Latour's "black boxes" (1988) in one, and Star and Griesemer's "boundary objects" (1989) in the other. These standardized packages—clustered around boundary objects such as genes or germs-appeal to experts and lay-people alike, linking together different social and theoretical communities in the service of shared meaning. Without rigorous standardization, however, they can fall prey to definition slippage. Rather than the black box of fact, or the elastic relationship of a boundary object, a standardized package "handles both collective work across divergent social worlds and fact stabilization ... [in] a gray box which combines several boundary objects" (Fujimura 1992, 169, emphasis in original). Recent work shows that these standardized packages of boundary objects can be instrumental in the construction and contestation of identity: DNA and concepts of "blood relation" have been deployed as a boundary objects in the formation of identity among Native American populations (Reardon 2004; Reardon and TallBear 2012; TallBear 2013), and as tools in the "geneticization of 'race' and ethnicity" (Nelson 2008, 771; see also Nelson 2016; Fullwiley 2008, 2011; Panofsky and Donovan 2017). Notably, though, these boundary objects are often not taken as unalterable "received facts" (Dumit 2003), but rather used in conjunction with other types of knowledge (e.g. historical, cultural) allowing people to "enact a course of deliberate and strategic negotiation in an effort to create kinship orientation ... [that] attends as well to the weight of individual desires for relatedness (Nelson 2008, 771). Similarly, Otherkin science creates a standardized package of acceptable claims and reasoning-via boundary objects like phantom limb syndrome and multiverse physics - that links seemingly incompatible systems into a stable Otherkin scientistic self, attaching scientific validation to a desire for relatedness to others experiencing a selfhood so far removed from the mainstream.

The Otherkin perpetually negotiate and construct Otherkin science, suspended between the observable limits of the physical human body and the subjectivity of personal experience. While they experience their lives in a manner wholly anomalous to the laws of mainstream accepted science, they must still reconcile this experience with those same laws that govern their 
understanding of the larger world. This requires constant positioning between the poles of experience and knowledge, metaphysics and physical science, the spiritual and the neurological, ontology and epistemology. They establish and maintain this tenuous position through debates revolving around legitimate definitions of Otherkinity-debates that often manifest in the policing of those they call "fluff" as exemplars of inauthentic or unreasonable "kin identification. The Otherkin case is striking not only because of its obvious distinction from normative Western human experience, but also because it illustrates how networked media technologies can be utilized in the construction of scientific fact through the policing of group boundaries. Having no central authority framework, the Otherkin community relies on localized platform administrators (Admins) to uphold group norms and definitions, which unavoidably drift in different contexts. As boyd reminds us, "digital networks will never merely map the social, but inevitably develop their own dynamics through which they become the social" $(2008,155)$. Simply put, The Otherkin represent in many ways both the hope and the danger of Internet sociality: collapsed geography affords a context where people of similarly marginalized experiences can cohere, but the near limitlessness of digital space creates a situation wherein maintaining cohesion becomes exhausting, if not unattainable.

The following traces the construction of Otherkin science-through the dual processes of boundary work and the standardizing of packages-in four sections. The first, "Otherkin Facebook," includes a brief history and current status of the Otherkin Internet community, particularly on Facebook, revealing the practices of "questioning" and "grilling." The next section examines how this questioning in Otherkin Facebook groups helps the community patrol its members for inauthenticity, or "fluff." The third section, "Otherkin Science," focuses on the measures Otherkin use to validate non-fluff identifications, weighing subjective experience against empiricist evidence. This is followed by a section of conclusions, parallels, and implications.

\section{Otherkin Facebook}

This study comes as a part of five years of participant observation I conducted with the Otherkin community as a non-kin anthropologist. The community itself exists mainly in the Internet, on forums and social media platforms, and my fieldwork included engagement on Facebook, Tumblr, YouTube, Reddit, and multiple web-based chat forums, as well as the Second Life 3D virtual platform, and at face-to-face meetups and camping trips. This article, however, focuses

\footnotetext{
" "Fieldwork" in this context involved checking multiple social media accounts, commenting and posting, participating in conversations, conducting interviews, and sometimes attending scheduled meetings and events-the digital equivalent of what Geertz would call "deep hanging out" (1998). An issue singular to digital anthropology is the "searchability" of Internet text communication and its effect on the reality of perceived anonymity (boyd 2010). Due to the diversity of Internet context, I utilize a few different layers of anonymity in this article. Key interlocutors-anyone in the article with a name-have been given pseudonyms, chosen by themselves or with their input. I have likewise pseudonymized specific Facebook groups and connected group forums-like Kin Sanctuary and No Fluff Zone-to avoid unintentionally revealing personal information about members. People whose words I use from closed (i.e. non-searchable)
} 
specifically on the Facebook aspect of the research. While the Internet can be seen as the Otherkins' main space of social activity, it is important to note that the Internet did not invent the Otherkin. They trace their community's beginning to the Elf Queen's Daughters, a group who identified as elves back in the early 1970s. The term "otherkin" came about in 1990, as a part of the Elfinkind Digest email listserve (Scribner 2012). A small group of users on the alt.horror.werewolves newsgroup "came out" as wolves in 1993, inadvertently beginning the Otherkin online community, which spread to web forums and Internet Relay Chats over the next decade. Some of these have been online since the late 1990s and are still active. Aside from these forums, the most active online Otherkin related sites are the social media outlets Tumblr and Facebook.

I choose to look specifically at Facebook for two reasons. First, as the dominant contemporary social media platform (Pew Research Center 2018), Facebook has deeply influenced the way we in the Internet-using world regard interpersonal relationships (Gershon 2011; Brison 2017; Miller 2017), presentation of self (Dalsgaard 2008; van Dijck 2013; NurMuhammad et al. 2016; Miller and Sinanan 2017), political engagement (Bode 2017; Engesser et al. 2017), and even death (Haverinen 2014, 2015). Second, and more specific to the Otherkin, Facebook features the ability to form "groups" and regulate their privacy, creating relatively safe-and easily policed—spaces for Otherkin discourse. Though Facebook affords these tools, it is important to note that I am not viewing the platform from a technological determinist stance, but rather, following Baym (2010) and Lingel (2017), a perspective of "social shaping" wherein "the consequences of technologies arise from a mix of 'affordances'-the social capabilities technological qualities enable-and the unexpected and emergent ways that people make use of those affordances" (Baym 2010, 44). So the Facebook platform helps shape the ways in which the community socializes, but only through the Otherkins' specific choices about how to use it. In her work with countercultural online communities, Lingel reveals how Internet technologies can be deployed for "tactical" purposes within the dominant culture's "strategic" construction of those same technologies (Lingel 2017; see also de Certeau 1984). Specifically, Lingel examines how some drag performers from Brooklyn fought against Facebook's "real name policy" by tricking

group postings but could not obtain permissions from are simply referred to as "Original Poster (OP)" or "Mem" (for "Member"). Likewise, I refer to "interviewees" when quoting people who spoke to me directly but prefer to remain anonymous. When quoting from searchable blog posts and websites, I cite the author just like any other published source. In cases where publicly available (i.e. searchable) content could reveal the identity of an interlocutor, I paraphrase, attempting to keep the original intent and style while obscuring the searchability of the text.

10 While any current discussion of Facebook would need to reference the fact that user information had been purchased and used by Cambridge Analytica to influence the 2016 United States Presidential election, these revelations had not yet come to light during the research period, and thus did not affect the data germane to this particular project.

"Facebook's "real name policy" —now called the "authentic name policy" — states that it is a community where "everyone uses the name they go by in everyday life. This makes it so that you always know who you're connecting with and helps keep [the] community safe" (Facebook 2017). Further, the policy stipulates that a user's profile name should be "the name that your friends call you in everyday life ... [and] should also appear on an ID or document from our ID list. Nicknames can be used as a first or middle name if they're a variation of your authentic name (like Bob instead of Robert). Pretending to be anything or anyone 
the platform into thinking they were in Indonesia (where single-word names are allowed), thus using the platform tactically to circumvent its own strategic construction. Following Lingel, I view the Otherkin as a "community of alterity" — defined through "Otherness" from the mainstream Internet public, and also "authenticity" from within the group itself (Lingel 2017, 710) - and view their use of Facebook groups as tactical in nature, both blocking Othering agents from outside and assessing authenticity from within.

Even in an Internet culture that can be best described as "ambivalent" (Phillips and Milner 2017), the Otherkin are polarizing figures, and their Othering (often in the form of mocking and harassment) is pervasive. People often speak of Otherkin as "special snowflakes," a term-which has recently moved into popular parlance through the alt-right/Fox News cultural conduit-meaning a very fragile person who will do or say anything to appear unique and special. Otherkin-themed subreddits (smaller topic-based forums on the Reddit platform) specifically discuss some of the more bizarre Tumblr claims in a derisive light. YouTube videos produced by Otherkin are remixed and re-circulated with new user-made subtitles ridiculing the content and suggesting that Otherkin are either mentally ill or simply lying. Issues with harassment and cyberbullying are not exclusive to the Otherkin community, but Otherkin griefing is particularly dismissive, and at times violent, aggressively advising suicide. The abovebranded "ambivalent" Internet public shrugs off much of this behavior as "trolling," implying that it is not done seriously, and should be understood as a regrettable, but unavoidable, byproduct of the medium itself. Phillips and Milner explain the danger in believing this label:

"trolling" as a behavioral catch-all is imprecise and, in terms of classification, ultimately unhelpful. Further, as it often posits a playful or at least performative intent ("I'm not a real racist, I just play one on the internet"), the term also tends to minimize the negative effects of the worst kinds of online behaviors. (2017, 7-8)

This is not to say that the Otherkin do not experience trolling, but that these behaviors are better understood in the category of harsh "punching down" that many marginalized people experience at the hands of dominant groups $(2017,14)$. Due to this climate of harassment, Otherkin Facebook groups are often "closed"-meaning a person needs Admin approval to join—and community member Admins work diligently to ward off impostors by deleting comments and selectively denying membership.

Another problematic aspect of trolling's imprecision as a classification is how hard it is to tell intended mockery from harmless mischief. In the following example from Kin Sanctuary, a

isn't allowed" (2017). This policy affected many communities, specifically Native American and LGBTQ+ Facebook users (Haimson and Hoffmann 2016; Phillip 2015). In 2014, Facebook began cracking down on users in violation of this policy and suspending accounts, which also had a disastrous effect on Otherkin Facebook groups. Because Otherkin rarely use their legal human names in the community, a large portion of their accounts were declared "unauthorized." Chats and friend lists fell apart as everyone's name suddenly had to be changed into something that resembled a "real" name, in an attempt to prevent being caught up in the purge. A user named Draconex, for instance, would change it to something like Drake O. Nex. 
closed group I belong to, (Admin) Fei temporarily blocks a member (henceforth, "Mem") for making troll-like jokes:

Fei: $\quad$ This still sounds trollish. I'll remove you guys for now.

Mem 1: well if you wanna be paranoid coz of banter thats your choice but not a very nice choice

Fei: $\quad$ I don't think you understand the situation. We've been dealing with trolls a lot lately thanks to this new organized movement to troll otherkin groups, and when you deal with trolls a lot it becomes pretty easy to spot them.

Mem 1: i understand where your coming from all i can say is me and [Member 2] are just joking around

Fei: Well I've removed [Member 2] as he also appeared to be trolling. If he asks to rejoin I'll let him back in after the troll activity dies down.

Mem 1: fair enough

This interchange exposes how complicated safeguarding against trolls can be. The supposed threat of organized anti-Otherkin troll factions demands Fei's zero-tolerance approach toward shenanigans, even in a forum that generally encourages humor. In this situation, the member implied that he becomes "cookiemonsterkin" when stoned-an obvious joke that would probably have been benign at another time. In this particular context, however, the joke could be taken as a disparagement of the underlying concept of Otherkinity, rather than merely a comment on marijuana's effect on the appetite. The exchange also shows that, despite minor protest, the member understands the perceived necessity of the situation, which speaks to both the effect of trolling and to the power of group Admins. I heard many claims over the course of my fieldwork about these organized anti-Otherkin troll factions. Some even maintained that trolls were being paid to troll specific groups. I never saw any evidence of unified troll movement, but the constant perception of impending trolling has a palpable effect on the community. It serves as a constant reminder of their own Othering at the hands of mainstream culture: "trolls are born of and embedded within dominant institutions and tropes, which are every bit as damaging as the trolls' most disruptive behaviors ... Online trolling is par for the mainstream cultural course" (Phillips 2015, 11). Sometimes the case-by-case interventions proved insufficient, and more drastic measures of policing had to be taken, as shown in a recent update to the "description" panel of Kin Sanctuary: "Due to a high volume of trolls lately, this group will not be accepting any new members until further notice. DO NOT REQUEST TO JOIN OR YOU WILL BE BLOCKED IMMEDIATELY."

When I applied to join Otherkin Facebook groups, I was told by several of the Admins that I should write an "introduction post" upon my approval, so I posted something about my research, including a link to informed consent and IRB materials. This is not what the Admins meant, which soon became clear as I noticed these "introduction posts" popping up every few days in different groups. They seldom varied from a general template: 
Hello, everyone, my name is [whatever name the member goes by in the community, usually not their legal name].

Thanks for the add! I am a [Here the person provides a detailed description of their kintype. This description usually involves evidence in the form of visual details, how they experience the kintype and for how long, as well as some theories as to why this kintype (or Otherkinity in general) exists.]

If you have any questions, feel free to ask!

The other members in the group then comment on the post. Recently, both Fei and Petra (another key interlocutor and Admin) were added to a group to take over as Admins, so they had to write short introduction posts:

Fei: I'm Fei and I've been a part of the otherkin/therian community for 10 or 11 years now. I identify as a tundra wolf, snow leopard, fire nymph, and abrahamic angel. I personally believe my kinity to be spiritual due to reincarnation, but I also accept that it may be partially or entirely psychological. I experience mental shifts, phantom shifts, past life memories, species dysphoria, and possible dream shifts cause I do tend to appear as my kintypes in my dreams.

Petra: For those who don't know me, I've been a member of the greater otherkin community since about 2004 and identify as an African lioness and black tip reef shark for reasons relating to the brain.

These introductions receive respectful "likes." No one pushes back, questions, or even comments. Both Fei and Petra are known in the community, making the introduction posts largely a performative act of "passing the baton." But they are also modeling the correct way to introduce one's self. Fei provides an evidentiary and experiential laundry list, while Petra simplifies hers with the brief "reasons relating to the brain." If a new member's introduction is phrased similarly, the comments are welcoming: “Greetings!" "Welcome!" "Good to meet you!" "Hooray, another [kintype]!" If there is some doubt, due to a lack of information or something that didn't seem quite right, the OP of the introduction will be "questioned." Questioning is a customary process wherein the OP is asked direct, pointed questions about their Otherkin identity. And there are wrong answers. Common questions include: "How did you come to the conclusion that you are [kintype] or that you identify as non-human at all?" "What specific experiences brought you to this conclusion?" "What research have you done on this creature?" and "Have you considered other, human-based explanations for your experience?" For instance, OP2's introduction at the beginning of the article began without enough information, so she was (mildly) questioned with "Nice to meet you! What's a pterolycus?" and "Ah ok. So how'd you figure out your kintypes?" to which OP2 responded sufficiently. If the group can come up with a reason that the OP does not fit the definition of Otherkinity, they tell the OP in plain terms that either they are not Otherkin, or they need to do more research and figure out their true kintype.

While the practice of questioning may seem counter-intuitive, as it could make people feel unwelcome and dissuade membership, many Otherkin see it as a necessary step for a few reasons. The first is to weed out trolls, thinking they will expose themselves inadvertently with 
their answers. Otherkin have also suggested to me that questioning newcomers helps them learn about themselves. An awakening - the process through which a person realizes their specific kintype(s) - is an ongoing process, and the practice of questioning acts as a kind of sounding board for people to test the logic of their conclusions. Many older 'kin I have talked to lament the current state of questioning as too lenient, letting things slide that would have been unacceptable previously. Several years ago, the act of questioning was actually called grilling, and was apparently much more intense, a sort of harsh hazing ritual that led to substantial selfknowledge. As Petra defines it, "grilling is the process of asking many and detailed questions to new members of the community, historically on a forum. It isn't just asking questions, it's literally picking apart every detail of someone's story." Another veteran member recalls her memories of this process in a post:

When I joined a few groups on Facebook as well as other forums, I was grilled until I wanted to cry ... I could not come up with a valid reasoning for my beliefs at that point. It took some time, but I was able to come up with valid, "non-human traits," if you will, after sitting down and considering what made me really think what I was was " $\mathrm{x}, \mathrm{y}$, or $\mathrm{z}$."

In this poster's experience, the grilling was harsh, not because she felt she was being bullied or doubted, but because she could not come up with a "valid" rationale for her beliefs. This raises the question: What does "validity" mean to her and who grants it? We could assume that validity in her case comes from Admins and group members, but where do they base this standard? It seems her own subjective experience does not qualify as valid, so it must come from some outside source. Petra argues that the only real way to achieve validity is to have it bestowed by empirical scientific study:

Something being valid implies it has been validated. This means that studies have been done on the nature of it and have proven it is a thing. This does not yet apply to the subject of otherkinity, so to call it valid is incorrect.

So, if actual validity is not an option for Otherkinity (to Petra, at least), how do Admins and group members judge what would be considered valid reasoning for a new member's kintype?

Early in my research, Petra suggested that I try to approach, "people who encompass every major kintype ... all of whom should be grounded in rationality." In the absence of empirical study, rational logic makes a claim reasonable. Discussions of Otherkinity consistently display dependence on and respect for rationality and reason, with assertions often being judged based on their logical flaws. In a similar fashion, Collins et al. have traced how proponents of "fringe science" (e.g. alternative physics) have strived "to recapture the rationality of its proponents, showing how, in terms of the procedures of science, they could be right and the mainstream could be wrong and therefore the consensus position is formed by social agreement" (Collins, Reyes-Galindo, and Bartlett 2016, 1). This kind of appeal to rationality serves to reframe seemingly fanciful (or irrational) notions within a system that renders them reasonable (rational). 
Likewise, the Otherkin practice of questioning filters something that first appears dubious through an approved and formalized process, translating it into something rational.

Most often, interlocutors and interviewees told me that the purpose of questioning is to preserve a bounded and approved definition of what counts as legitimate Otherkinity (a standardized package). As one member explained to me, "It's not because we hate people different than us, it's because there IS a definition to these labels, and to not follow them means they mean absolutely nothing." Since the move in recent years from grilling to the much more inclusive questioning, the community has seen the growth of explanations that would have previously been rejected outright—claims such as physical shape-shifting, super-human senses, and identification as inanimate objects. Grilling once served the purpose of stopping these supposedly incorrect identities from flourishing, but that is no longer the case. The same grilled veteran community member from above who worried about "valid reasoning" posts:

I lurk through a few forums and it seems like NO ONE is being questioned about their discovery anymore. It's very disturbing to me that a lack of analysis is seemingly encouraged in forums dedicated to seeking further knowledge about one's therio-/kintype. In my opinion, open acceptance in an introduction can lead to further ignorance when it could be corrected and fixed from the moment a new person joins a group/forum.

Petra, even with her long history in the community, thinks she just missed those glory days of universal grilling:

Things before I came along were all about grilling and constructive conversations and the like but those people who were rubbed the wrong way revolted and formed their own forums of over acceptance, going in the complete opposite direction. These days, you ask the basic "so how did you come to X conclusion?" and some kids go "don't grill me!"

This "complete opposite direction" is the same "further ignorance" the previous member feared, and it has a name: "fluff."

\section{Fluff}

The majority of the "work" in boundary work is, as previously mentioned, "constructing a social boundary that distinguishes some intellectual activities as 'non-science'" (Gieryn 1983, 782). In Otherkin science, this is no different: the first step in constructing legitimate Otherkin science is the demarcation and definition of Otherkin non-science, or fluff. An informational word document passed around the Otherkin Facebook groups called "Common Terminology" defines a "fluff" as:

Something that is not apparently genuine (real, true). "Fluff" is also defined as an individual (usually self-identified 'Kin or Therian) who is misled, closed/refuses to learn and may be varyingly delusional (delusion is defined as holding beliefs or ideas despite 
evidence to the contrary-basically rejecting facts). Example: Someone who truly thinks they can break the laws of science (Nightside 2015).

In my interviews, I have been given many definitions of what exactly fluff is: "Kin that believe so desperately in logical fallacies that no outside questioning will budge them. They're too focused on being unique and special to actually learn"; "slang for those who are "fake therians' or just confused about it and mostly who are obsessed with wolves and think they can physically shift into one which is delusional"; and "made up stuff, essentially anyone who isn't otherkin and just trying to fit in for one reason or another." Petra specifically bases the designation on logic and evidence, indicting "anyone making extraordinary claims with no evidence or hyper spiritual claims with no semblance of logical thought ... [who] instead think they can just make up 'facts' and twist terms as they go." Note the upheld dichotomy of logical fallacy vs. the laws of science: logical, informed, factual science = Otherkin, while delusion, made-up-stuff, and logical fallacy = fluff.

The word "fluff" comes from a shortening of the term "fluffy bunny" from the Pagan/Wiccan community (Coco and Woodward 2007; Snook 2015). In their study of Australian Pagans, Coco and Woodward found that groups used "fluffy bunny" as "a shorthand way of signaling people's inauthentic engagement with witchcraft" $(2007,501)$. Fluff holds a similar significance for the Otherkin. The first online reference to Otherkin fluff was the creation of the (now defunct) Anti-fluff DragonKin online mailing list in 2002, specifically set up for Dragon Otherkin who are "tired of the kids under 18" (Scribner 2012, 64). Like the Pagan fluffy bunny, the prototypical Otherkin fluff is young, misinformed, and largely influenced by mass media portrayals. Many specifically attribute an influx of young fluff to MTV's Teen Wolf and the Twilight book and movie franchise. Both feature conventionally attractive shape-shifting teenage werewolves as protagonists, leading community members to be wary of newly awakened wolf therians' ideas about Otherkinity. There seems to be a tacit understanding that many novices enter the community with wolf kintypes, but outgrow them. Older 'kin will admit to initially entering the community as wolf therians, before they did enough research to figure out their actual kintype. It is such a common occurrence that they have a specific term for young fluffy wolf therians-wolfaboos—described here by an interviewee:

Teen wolves/woolfaboos. I think they are the worst out of everyone. $99.9 \%$ of the time they're just angsty, emo, closet furry, teens with an animal play kink who make these ridiculous packs with the most absurd names like "Death Watch Ember Valley Pack" and the alpha is named "Silver Moonwhisper."

Frustration with fluff and wolfaboos is understandable: at stake in Otherkin representation is not merely an opinion about how the community should be characterized, but the very idea that Otherkin identification is a viable way to exist in the world. A community that constantly faces derision and disbelief from the outside world must be seen as a unified front, and as one member puts it, "Fluff ultimately makes us all look bad. I sure as hell don't want to be associated with that." Fluff represents ignorance to many in the community. It gives fuel to those 
on Reddit and YouTube who search for the most outlandish Otherkin claims. These tensions support an "us-and-them" Manichean position that one interviewee expresses: "they create their own definitions for what our community is and spread the misinformation around and send anon hate to the actual members of the community who try and correct them. We become mean, gatekeeping, greymuzzles."

Facebook lies at the front lines of this split. While the majority of Otherkin on the older forums maintain a stricter definition of Otherkinity, the Otherkin who present on Tumblr are generally more accepting, and allow an immensely augmented diversity of identity possibilities. This is not simply an issue of age, but also of platform affordance: Tumblr-being primarily a blogging platform-allows for free expression without much oversight, whereas the Otherkin online forums are traditionally Admin-ed by respected community members or site owners. Otherkin Facebook groups act as a bridge between the two: Facebook's social media ubiquity attracts younger Otherkin, and Facebook's group system allows for Admin control of the content. Bringing together members from both camps, these groups become the sites of much boundary work in the form of fluff policing. Many of the larger Otherkin Facebook groups are Admin-ed by members of the old guard, simply because they have been around longer, so new Otherkin who have only been exposed to Tumblr are taken aback by the aggressive style of questioning. Sometimes they push back, and the conversation can quickly become combative (as was the case with OP1 at the beginning of the article). More often than not, the questioned OP will call the Admins and group members elitists or bullies. The group will respond with calls to rationality and references to posted group rules. In some cases, the Admins ban the OP permanently, but only after a solid rebuke. In the following excerpt, Fei gives an OP one of these scoldings:

OP: if $u$ have a problem with me and don't see eye to eye with me then kindly don't reply to a comment I post ... I don't like ppl trying to correct me if $\mathrm{u}$ want to start a debate or state facts I'm not the person to do it with

Fei: $\quad$ This is a group for logical people who accept and understand facts. If you can't handle that, get the fuck out. We will not change for you.

... The whole community of real otherkin are this way and you will have this problem everywhere you go.

You need to grow up and accept that the otherkin community is for logical people who take their identity seriously, not for whiny children who insist on living in a fantasy world.

The OP is not specifically called fluff in the excerpt, but is described as such several times in the ensuing discussion thread. Here we see, again, the claim that the OP (as fluff) is young, irrational, and indulging in fantasy. More than that, this example frames the issue as one of community solidarity - "the whole community of real otherkin are this way" - the salient word being "real." The OP would probably be able to find Internet spaces where their views would be

12 A Greymuzzle, as defined by one FB group member is, 1) A therian (or furry as they also use it) older than 35-40. 2) Someone who has been in the community for $10-15+$ years. 
tolerated, but those sites are not for "real" Otherkin, who are logical and scientific. This particular group, No Fluff Zone, is purportedly a space for real Otherkin. The group rules are "pinned" to the homepage-meaning that they will always appear above all other posts-with the warning that breaking a rule will result in a ban. The first rule, listed in all caps, is "NO FLUFF ALLOWED" recalling the description of the original 2002 Anti-fluff DragonKin email list, which explicitly stated, "Fluffiness is not allowed here" (Scribner 2012, 64).

What we see going on with fluff on a more abstract level is the bolstering of empirical scientific method through the delegitimizing of its supposed opposite. Framing non-science not as a set of beliefs or practices, but rather as a type of person who characterizes them, the Otherkin experts accomplish the "monopolization of professional authority" (Gieryn 1983, 792). They put allegedly implausible Otherkin through a ritual of accusation, mockery, and public shame. Notably, the lay-experts do not bring the science itself into question and therefore maintain a rational stance. It allows the negotiation to be centered on identity, rather than problematizing scientific logic itself. But beneath these contestations lie the beliefs and practices behind the identities, and the construction of Otherkin science itself.

\section{Otherkin Science}

It should be clear at this point that the first rule of Otherkin legitimacy is to not claim the ability to physically transform. The concept comes from media portrayals of werewolves, vampires, and shape shifters, and instantly hoists a red "wolfaboo" flag. Here, a Facebook group member loses patience with claims of physical transformation from a wolf therian:

Mem 1: No. Honey, I'm old and I'm going to be blunt. Werewolves do not exist. Nobody who ever lived or will live can physically shift.

OP: $\quad$ Everyone's belief is different my friend! :)

Mem 1: Put your p-shift on youtube and I'll publicly announce my belief in real life werewolves! :)

When faced with the OP's resistance, the group member says what any good scientist would: show me proof and I'll believe you. This speaks to the distinction at the heart of Otherkin scientific construction-the difference between belief and knowledge. While young fluffy wolf therians may sincerely believe that with enough effort they could physically shift, they do not know that they can, because no evidence exists of anyone ever actually transforming. This kind of evidence-based knowledge is what experienced Otherkin community leaders would require to believe such claims: recall Petra's earlier standard for "validity." Further, the type of evidence they demand is visual proof, the very observational empirical knowledge at the foundation of science (Shapin and Schaffer 1985). Note how-of all the available Internet media-the group Member above asks for p-shift evidence on YouTube, a fundamentally visual platform. When I asked interviewees about fluffy claims and behavior, they came up with very similar calls for scientific evidence, as shown in these responses: 
The only things I am very skeptical about is physical shifting and magic, and other things that can easily be reliably disproven through empiric testing.

Physical shifting-well not at all since it is impossible. Claiming to have supernatural powers is also something to not really believe unless they can provide solid evidence.

It's one thing to feel or subjectively experience something in your mind or spiritually, but making physical claims doesn't sit well in the otherkin community. Things like claims of physical shifting, claims of not being human physically, etc. does not sit well with me. Real-life, physical claims require evidence to back it up.

Breaking the laws of physics is not up for discussion unless the claimant can provide proof, which, of course, they never can. Thus, the demand for proof ("evidence," "empiric testing") is a conversation ender, and often results in a ban. Even a harsh rebuke, however, allows for future scientific validation through evidence. Here, a Member responds to another unproven and implausible claim:

Mem 2: You say we're not believers, when really, if you could provide honest to god proof of it occurring, most of us, if not all of us, would gladly start believing. You cannot make extraordinary claims without providing extraordinary proof ... But for now, you're nothing but another raving delusional person with unsubstantiated claims of grandeur. Don't like being labeled as such? I'd get working on that proof, if I were you. Or better yet, feel free to shut up and get over it.

As mentioned earlier, in the absence of empirical evidence (i.e., in every case), the layexperts in the community demand logical reasoning. And to truly substantiate a claim, this reasoning comes as the product of an appropriate amount of research. What this means differs according to context, but usually involves archival study of species' morphology and behavior, a long process of elimination, and logical argument. Notably, it is important not only to do the research, but also to have the knowledge of what kind of research matters for legitimacy. While less immediately damning than p-shifting, the attribution of unrealistic morphology or behaviors to a kintype is said to characterize "people who have not put in enough research and critical thinking to actually know their kintypes, people who claim something that would not be true for their kintype." This is primarily an issue for therians, since they have representations of their animal kintypes living in the world for comparison. Common mistakes that separate wolfaboos from legitimate wolf therians, for instance, include wolves with red eyes, asserting a kintype has a fur pattern that does not match with the species, or claiming certain solitary animals run in "packs." In one long Facebook chat I facilitated, someone claimed to be the "alpha" of a "pack" of wolf therians, and another member simply attached a bibliographical listing with online links to eight scientific articles and videos about how canines don't actually form packs. A sarcastic "Wolfaboo" meme circulated in some Facebook groups features the quote "My wolf is a black 
arctic wolf with blue eyes that howls at the moon." The problems with this claim are that arctic wolves are white, do not have blue eyes, and that wolves actually howl at/for each other, not at the moon. In a case like this, the claimant would be told to do more research and try back later.

It is not enough, though, to demarcate fluff and fluffy beliefs as non-science through boundary work: it is also necessary to define what is science for the Otherkin, which is where the standardized package of boundary objects comes into play. In the case of Otherkin science, these boundary objects come from psychology, physics, biology, metaphysics, and contemporary social theories. In the deployment of these collected objects, the assuredness of legitimacy follows a hierarchy:

1. Claims that can be proven empirically

2. Claims that can be logically justified using science that has been proven

3. Claims that can be defended using abstract science

4. Claims that (however metaphysical) cannot be disproven with science

All else is non-scientific, therefore illogical, therefore fluff.

Claims that meet the first condition are not very common among 'kin that I have talked with, because they require the assistance of the medical/scientific industry, and many Otherkin do not seek "help" in this way. To seek out a professional therapist or doctor would involve "outing" oneself and even risking possible institutionalization. The rare cases I am familiar with are usually situations wherein the person has been diagnosed with a known disorder, such as Dissociative Identity Disorder (DID), and the kintypes are explained either as associated neurological symptoms or accommodated as a type of coping strategy. While the empirical value of such a diagnosis could be questioned, it is the closest that the community comes to straightforward scientific validation.

Many in the community use the second tier of the hierarchy-that the explanation can be logically justified using current (though unrelated) empirical scientific knowledge. Petra explains her kintype as a primarily neurological phenomenon, and uses pre-existing science on the human brain to bolster her claim:

The thing about a psychological/ neurological explanation for otherkin, is that the principles are already there that can explain what is experienced (such as phantom limbs, dream shifts, out of body experiences (astral travel), etc.). They have yet to be specifically studied with relation to otherkin, but the principles themselves have been studied and documented.

Because these seemingly metaphysical or even mystical experiences can be explained in relation to other neurological conditions, they are imparted a measure of legitimacy. Many of my 'kin interlocutors relay anecdotes about phantom wings and tails that would, at first, seem farfetched, but when related to non-kin stories of human phantom limbs, they become thinkable as neurological phenomena. The major difference in these accounts is that, in the case of a phantom 
human limb, the appendage was at some point tangibly attached to the body, connected physically to the brain through a network of nerves. Taken on its own terms, however, the neurological experience of phantom limbs, whether arms or wings, would be similar in sensation. Observe how a dragonkin interviewee describes his phantom limbs and offers a possible explanation:

I do get phantom limbs occasionally though they've ebbed a lot in the last few years and I mostly experience them as phantom wings when the wind is particularly strong or I am on a mountain ridge or the like... When I was trying to figure out the details of my horns and hands and feet and legs several years ago, I started getting phantom sensations there, probably because I was thinking a lot about them. I could imagine my feet grasping onto things like a lizard's. My current theory is that phantom limbs are the result of the brain imposing its vision of itself so it's something that's caused by identifying as a dragon.

This account of dragon identification would be deemed legitimate, because it is situated alongside a neurological explanation. He reasons that his phantom wings and reptilian feet are a product of his own brain, an argument that concurs with the psychological "neuromatrix" explanation of phantom limbs (Melzack 1989).

Fei also acknowledges this relationship to neurological explanations, though for her it manifests as an issue of gender identity:

I have found my species identity to be very similar to my gender identity (I'm also transgender). We now know that gender identity is primarily neurological, so it's likely that otherkinity could be a similar neurological phenomenon, which is why I would like to see neurological studies on otherkin.

Otherkin make parallels to transgender identification often, claiming that the experience of gender dysphoria - "the distress that may accompany the incongruence between one's experienced or expressed gender and one's assigned gender" (American Psychiatric Association 2013, 451) - is similar to what they call species dysphoria. The experience of species dysphoria is exactly what it sounds like: incongruence between a person's human body and their non-human identification. This parallel was bolstered by a psychological journal article (Gerbasi et al. 2008) that put forth the concept Species Identity Disorder (SID) after interviewing participants at a furry ${ }^{3}$ convention. This article was roundly critiqued a few years later (Probyn-Rapsey 2011) for its questionable methodology and its reliance on Gender Identity Disorder (GID), which frames trans identifiers as disordered and is no longer an approved diagnosis. Rather than viewing this as a

${ }^{13}$ Furries and Otherkin are not the same thing. Furries have an affinity towards an animal, whereas Otherkin identify as the animal. Some people can be both, but most are not. A furry enjoys anthropomorphic art and aesthetics-usually a cartoon-like being with the head, paws, tail, etc. of an animal, and the body shape of a human. Many furries also like to dress in fursuit costumes that express their fursona, which is not to be confused with a kintype. For more on furries, refer to Healy and Beverland (2013) and Roberts et al. (2015). 
reason to abandon the idea of SID, the Otherkin community largely sees the de-pathologization of GID as a hopeful future of legitimacy. Fei continues:

Being transgender is no longer classified as a mental illness because it typically does not significantly interfere with one's ability to function ... Otherkinity is also not likely a mental illness because it also does not significantly interfere with one's ability to function, and given that we're aware we are physically human, there is no evidence that we're delusional either.

While many in the community find trans and Otherkin identities easily comparable, some argue that distinctions still need to be made. Lady, who is also transgender, agrees with Fei that Otherkin identification is not disordered, but warns against conflating species and gender:

Personally, I would probably classify it as an aspect of neurodiversity, rather than pathologizing it unless it had major and negative impact on someone's life. I often worry that people create false parallels between transgender and otherkin experiences. ... As someone who is both otherkin and transgender, while my two forms of dysphoria have some similarities, they are also very distinct from one another ... they are separate intersectional identities.

Rather than relying solely on the "hard" sciences, Lady makes a case for neurodiversity and intersectional feminism. Even so, she uses the psychological language of dysphoria as a link to authoritative neurological science. In these discussions, we see phantom limbs, dysphoria, gender identity, and related neurological phenomena being deployed as boundary objects that contribute to the standardized package that is Otherkin science, tethering it to validated scientific concepts.

Otherkin view arguments and justifications of 'kinity as falling into two camps: the psychological and the spiritual. While the reasoning above obviously sides with psychological explanations, I maintain that the more spiritual explanations (termed so by the Otherkin) also depend upon scientific knowledge to legitimize their claims. Thus, the spiritual camp works at the third and fourth tiers of the aforementioned scientific hierarchy: 3) claims that can be defended using abstract science, and 4) claims that (however metaphysical) cannot be disproven with science. The Otherkin's most commonly referenced bit of abstract science is the multiverse theory from physics. Introduced by Schrödinger (and his cat) in the 1950s, the theory suggests that there are an infinite number of parallel universes playing out all possible realities. This is useful, because it gives credence to a great many Otherkin claims. For instance, 'kin who identify as elves, dragons, or other mythical creatures can use the theory to explain that there are other dimensions in which these beings exist. This is the power of the word "infinite," it means that absolutely everything is not merely possible, but definite. This is also the area where abstract science and metaphysics can overlap or clash. We can see the diverging, but ultimately respectful, viewpoints in a discussion of multiverse theory and the idea of an astral plane: 
Mem: The multiverse idea is prevalent in quantum physics and frankly makes a lot of sense to me

Petra: I believe in the multiverse theory as per physics. Otherwise, I believe other people believe in such things as the "astral" etc. I just don't.

Fei: I believe in other dimensions/realms partially due to my spiritual experiences (including astral travel), but also partially because as far as I can tell, 2 of my kintypes existed in separate realms from this one.

We can see here the blurry border between abstract science and pure metaphysics. Even Petra, who is normally quick to call up scientific or logical arguments, simply says she doesn't believe in an astral plane. Even though full acceptance of the multiverse theory would mean that an astral plane definitely exists somewhere, it doesn't quite feel scientific. It bridges the third and fourth level of the Otherkin scientific hierarchy. The addition of astral travel to accepted 'kin claims enables the majority of the fourth tier. If it is within comprehension that there is a place or state of being that allows a soul/creature to move while disembodied, many other explanations become thinkable. The most common of these is past-life regressive memories of life as a different being, often in a different dimension. Once the multiverse has been legitimized, and disembodied movement lends credence to the idea of reincarnation, how could someone scientifically disprove past-life memories? Indeed, at this point, couldn't they be explained as just another neurological manifestation of multiverse travel? And through these logics, multiverses, astral planes, and past life memories are added to the Otherkin science standardized package.

While these various explanations are situated at different levels of a scientific hierarchy, they are all uniformly accepted once the logical arguments have been made. A standardized package "consists of a scientific theory and a standardized set of technologies which is adopted by many members of multiple social worlds to construct a new and at least temporally stable definition" (Fujimura 1992, 169). When I asked interviewees what they considered to be legitimate Otherkin claims, they offered no indication that some were somehow more legitimate than others-the disparate boundary objects had congealed into a standardized package, as a collected theory of phenomena and technologies describing Otherkinity:

Legitimate otherkin experiences include phantom limbs, mental shifts, astral shifts, past life memories, somewhat "heightened" senses (the senses don't physically heighten, people just pay more attention to them during certain shifts), and species dysphoria.

Past-life memories, phantom limbs, astral projection, heightened awareness / senses are all optional elements that one may experience but they are not required

Concepts such as phantom limbs ... and past life memories (within reason) are all things that I feel a human being can experience, even if these experiences are often unusual and not universally culturally or spiritually accepted

Thus, after the process of scientific justification is completed, often through the practice of questioning or grilling, the identification is deemed valid. Those who use more "spiritual" (e.g. 
less "scientific") terms are usually asked more questions, and have to do more in-depth logical reasoning, but are equally validated at the end of it. Otherkin may have to repeat this process several times in different contexts, groups, and forums, but, once approved, they remain valid in the eyes of the group. They have already endured the rigorous logical hazing-tough but evidence-based and grounded in reason-the crucible in which their Otherkin scientistic selves have been forged.

\section{Conclusion}

A poll on the homepage of the website "The Otherkin Community" $(n=1,538)$ asks "Will Humanity Ever Accept Otherkin \& Metaphysics?" The largest percentage (23\%, n=359) say "humanity is too ignorant," but $21 \%$ (328) think it could happen "perhaps in the near future," and $14 \%$ (222) believe "they've already begun to accept" (The Otherkin Community, Inc. 2016). Unlike the conspiracy theorists driving the "alternative fact" and "post-truth" movements who would unseat the current holders of scientific authority, the Otherkin seek recognition from scientific institutions. They see themselves as part of a long history of science's vindication of previously ridiculous notions, stretching as far back as heliocentric theories to contemporary ideas about gender identity. Currently, trans identification serves as legible (though imprecise) metaphor for the Otherkin to explain their experiences, and it also represents a hope for recognition: scientific research is finding increasing connections between gender identity and the functioning of the brain, even in early adolescence (Nota et al. 2017). While many in the Otherkin community argue that their identity is "not valid until it has been validated," the insight provided by scientific research into trans neurology raises the possibility that such validation could actually happen in the future. For many in the trans community, however, the Otherkin represent a kind of fluff, the fringe at the periphery of body-dysphoric identity that threatens to frame them all as illegitimate or unreasonable. The Otherkin presently occupy a space beyond what Renée Haynes has called the "boggle threshold," "the point at which the mind boggles"the line we all draw that separates the plausible from the ridiculous (1980, 92; see also Luhrmann 2014). Where we draw these lines is different for everyone; it could be a belief in a higher power, telepathy, ghosts, or other-than-human identification. The Otherkin recognize that they boggle minds, but many still hope for future understanding. Bolstered by scientific findings and increasingly (albeit slowly) accepted by mainstream culture, trans identity represents a comparatively plausible identity construct, whereas identifying as another species is past the boggle threshold. The Otherkin know that current accepted science does not support their otherthan-humanness; they also know they experience life as other-than-human beings. These things are both equally true, so they must find ways to reconcile the two if they hope to ever achieve anything like the recognition they see in the LGBTQ+ community.

To repeat-for the sake of convenience-a scientistic self, rather than being objectively approached, begins with an acceptance of a subjective experience or belief, and deploys scientific theories, facts, processes, and methods to rationalize that experience. Nelson (2008) describes African American responses to genetic ancestry testing as "affiliative self-fashioning," meaning 
that they accepted the supposedly "objective" scientific results only to the extent that it affirmed prior understandings of their own lineage. Panofsky and Donovan (2017) see a similar negotiation in white supremacists' reactions to (what they consider) either "good" or "bad news" from genetic ancestry testing, using the language of the science to reinterpret and mitigate results of partial non-whiteness. Otherkin scientistic self-fashioning is constructed from the opposite direction. There have been no Otherkin scientific studies to react to, so they create a standardized package of Otherkin science themselves. It may seem at first that they take what they can from physics and metaphysics as needed to explain their experiences on an individual basis, existing in the spaces between boundary objects. In the absence of sanctioned scientific studies, however, it is incredibly important that they maintain strict definitions of Otherkinity, so a standardized package is necessary. The "grey box" of Otherkinity created by this package must hold, so, in the event that mainstream science shows interest, 'kin can state, "Otherkin experience involves these particular neurological phenomena and these particular metaphysical phenomena." They need to show that there are rules, and the practices of questioning and grilling act as the standardization process for these rules. While the "fluff" argue for boundless modes of identification that boggle contemporary ideas about existence, the established Admin class seek to uphold a more rational system of Otherkinity, wherein people's minds are pushed to, but not over, the brink of apprehension, using accepted science as a guardrail of sorts. The standardized package keeps that system bounded. What these Admins are doing is essentially demarcating a fringe within the fringe, thereby creating a space between established science and implausible whimsy where they can lay claim to their own scientific knowledge. In doing so, they fight a battle on two fronts: on the periphery, they fight trolls and scientific authorities for legitimacy through recognition; and from within, they fight fluff to maintain the standardized structure necessary for that same hardwon legitimacy.

The Otherkin are not the only people who look to science to understand themselves. We all do-through genetics testing, MRIs, X-rays, blood type, not to mention the entire field of psychology. The Otherkin are also not the only online community that challenges traditional conceptions of body and identity: the Internet abounds with neurodiversity, genderfluidity, and body-dysphoria. And they all-we all-are constantly in the process of constructing, negotiating, and disassembling our own scientistic selves, corroborating our daily experience with knowledge about how the world works. For some of us, this is relatively easy, but for others, like the Otherkin, it takes a great deal of effort, time, and complexity. The larger significance of Otherkin scientistic selves is that, through their construction and the creation of boundaries from within and without, we witness how groups (and the people within those groups) can carve out a space within which their own experiences-however seemingly irrational—can be apprehended; where they can render the unthinkable recognizable. 


\section{Author Biography}

Devin Proctor is a PhD candidate in anthropology at The George Washington University. His work explores the relationships between media \& technology, knowledge production, and subjectivity, drawn from five years of ethnographic engagement with the Otherkin community.

\section{Acknowledgements}

The author gratefully acknowledges all interlocutors, interviewees, and anonymous participants involved in this study (particularly Fei Novaya, Petra Carcharhina, and Lady Many Tails, who know who they are). I also want to thank my colleagues and mentors who read early versions of the article (especially Sarah Wagner, who read many versions, and whose patient brilliance is woven throughout), as well as the anonymous reviewers and the editors at ESTS for their careful and helpful comments and suggestions.

\section{References}

American Psychiatric Association. 2013. DSM-5: Diagnostic and Statistical Manual of Mental Disorders. 5th Edition. Washington, D.C: American Psychiatric Publishing.

Baym, Nancy K. 2010. Personal Connections in the Digital Age. 1 edition. Cambridge, UK ; Malden, MA: Polity.

Berger, Peter L., and Thomas Luckmann. 1966. The Social Construction of Reality;: A Treatise in the Sociology of Knowledge, New York, NY: Doubleday.

Bode, Leticia. 2017. "Closing the Gap: Gender Parity in Political Engagement on Social Media." Information Communication \& Society $20 \quad$ (4): 587-603. https: / / doi.org/10.1080/1369118X.2016.1202302.

boyd, danah. 2008. "None of This Is Real: Identity and Participation in Friendster." In Structures of Participation in Digital Culture, edited by Joe Karaganis. New York: Social Science Research Council.

—_ 2010. "Social Network Sites as Networked Publics: Affordances, Dynamics, and Implications." In A Networked Self: Identity, Community, and Culture on Social Network Sights, edited by Zizi Papacharissi, 39-58. London: Routledge.

Brison, Karen J. 2017. "Facebook and Urban Kinship in Suva, Fiji." Journal de La Société Des Océanistes 144-145 (2017): 209-20. https: / / doi.org/10.4000/jso.7707.

Certeau, Michel de. 1984. The Practice of Everyday Life. Translated by Steven Rendall. University of California Press.

Coco, Angela, and Ian Woodward. 2007. "Discourses of Authenticity Within a Pagan Community: The Emergence of the 'Fluffy Bunny' Sanction." Journal of Contemporary Ethnography 36 (5): 479-504. https: / / doi.org/10.1177/0891241606293160.

Collins, Harry, Robert Evans, and Martin Weinel. 2017. "STS as Science or Politics?" Social Studies of Science 47 (4): 580-86. https: / / doi.org/10.1177 / 0306312717710131. 
Collins, Harry, Luis Reyes-Galindo, and Andrew Bartlett. 2016. "The Ecology of Fringe Science and Its Bearing on Policy." ArXiv Preprint, no. arXiv:1606.05786 (June). http:/ / arxiv.org/abs/1606.05786.

Cusack, Carole M. 2016. "Spirituality and Self-Realisation as 'Other-than-Human': The Otherkin and Therianthropy Communities." In Fiction, Invention and Hyper-Reality: From Popular Culture to Religion, edited by Pavol Kosnáč, 1 edition, 40-57. New York: Routledge.

Cussins, Charis. 1996. "Ontological Choreography: Agency through Objectification in Infertility Clinics." Social Studies of Science $26 \quad$ (3): 575-610. https: / / doi.org/10.1177/030631296026003004.

Dalsgaard, Steffen. 2008. "Facework on Facebook: The Presentation of Self in Virtual Life and Its Role in the US Elections." Anthropology Today 24 (6): 8-12. https: / / doi.org/10.1111/j.1467-8322.2008.00626.x.

Daston, Lorraine J., and Peter Galison. 2007. Objectivity. New York, NY: Zone Books.

Davidsen, Markus Altena. 2013. "Fiction-Based Religion: Conceptualising a New Category against History-Based Religion and Fandom." Culture and Religion 14 (4): 378-95. https: / / doi.org/10.1080/14755610.2013.838798.

—_ 2016. "The Elven Path and the Silver Ship of the Valar: Two Spiritual Groups Based on J.R.R. Tolkien's Legendarium." In Fiction, Invention and Hyper-Reality: From Popular Culture to Religion, edited by Carole M. Cusack and Pavol Kosnáč, 1 edition, 15-30. New York: Routledge.

Dijck, Jose van. 2013. “'You Have One Identity': Performing the Self on Facebook and LinkedIn." Media Culture E Society 35 (2): 199-215. https: / / doi.org/10.1177/0163443712468605.

Dumit, Joseph. 2003. "Is It Me or My Brain? Depression and Neuroscientific Facts." Journal of Medical Humanities 24 (1-2): 35-47. https: / / doi.org/10.1023/ A:1021353631347.

Engesser, Sven, Nicole Ernst, Frank Esser, and Florin Buechel. 2017. "Populism and Social Media: How Politicians Spread a Fragmented Ideology." Information Communication \& Society 20 (8): 1109-26. https: / / doi.org/10.1080/1369118X.2016.1207697.

Facebook. 2017. “What Names Are Allowed On Facebook?" Facebook Help Center. 2017. https: / / www.facebook.com/help/112146705538576.

Fujimura, Joan. 1992. "Crafting Science: Standardized Packages, Boundary Objects, and 'Translation.'” In Science as Practice and Culture, edited by Andrew Pickering, 168-211. Chicago: University Of Chicago Press.

Fuller, Steve. 2016a. "Science Has Always Been a Bit 'Post-Truth.'” The Guardian. December 15, 2016. http:/ / www.theguardian.com/ science/ political-science/2016/ dec/15/ sciencehas-always-been-a-bit-post-truth.

2016b. "Embrace the Inner Fox: Post-Truth as the STS Symmetry Principle Universalized." Social Epistemology Review and Reply Collective (blog). December 25, 2016. https: / / social-epistemology.com/2016/12/25/ embrace-the-inner-fox-post-truth-as-thests-symmetry-principle-universalized-steve-fuller/. 
Fullwiley, Duana. 2008. “The Biologistical Construction of Race: 'Admixture' Technology and the New Genetic Medicine." Social Studies of Science 38 (5): 695-735. https: / / doi.org/10.1177/0306312708090796.

—_. 2011. The Enculturated Gene: Sickle Cell Health Politics and Biological Difference in West Africa. Princeton: Princeton University Press. https: / / doi.org/10.1515/9781400840410.

Geertz, Clifford. 1998. “Deep Hanging Out.” New York Review of Books, 1998.

Gerbasi, Kathleen, Nicholas Paolone, Adam Privitera, Laura Scaletta, Samuel Conway, Justin Higner, and Penny Bernstein. 2008. "Furries from A to Z (Anthropomorphism to Zoomorphism)." Society $\& \quad$ Animals $16:$ 197-222. https: / / doi.org/10.1163/156853008X323376.

Gershon, Ilana. 2011. “Un-Friend My Heart: Facebook, Promiscuity, and Heartbreak in a Neoliberal Age." Anthropological Quarterly 84 (4): 865-94. https: / / doi.org/10.1353/ anq.2011.0048.

Gieryn, Thomas F. 1983. "Boundary-Work and the Demarcation of Science from Non-Science: Strains and Interests in Professional Ideologies of Scientists." American Sociological Review 48 (6): 781-95. https: / / doi.org/10.2307/ 2095325.

Grivell, Timothy, Helen Clegg, and Elizabeth C. Roxburgh. 2014. "An Interpretative Phenomenological Analysis of Identity in the Therian Community." Identity 14 (2): 11335. https: / / doi.org/10.1080/15283488.2014.891999.

Hacking, Ian. 1995. "The Looping Effects of Human Kinds." In Causal Cognition: A Multidisciplinary Debate, edited by D. Sperber, D. Premack, and A. J. Premack, 351-94. Symposia of the Fyssen Foundation. New York, NY, US: Clarendon Press/Oxford University Press.

- 1999. The Social Construction of What? Cambridge, MA: Harvard University Press. . 2006. "Making Up People." London Review of Books, August 17, 2006.

Haimson, Oliver L., and Anna Lauren Hoffmann. 2016. "Constructing and Enforcing 'Authentic' Identity Online: Facebook, Real Names, and Non-Normative Identities." First Monday 21 (6). http:/ / firstmonday.org/ojs/index.php/fm/article/view/ 6791.

Harding, Susan. 2001. The Book of Jerry Falwell: Fundamentalist Language and Politics. Princeton: Princeton University Press.

Haverinen, Anna. 2014. "Memoria Virtualis - Death and Mourning Rituals in Online Environments," August. http:/ / www.doria.fi/handle/10024/98454.

—_. 2015. "Facebook, Ritual and Community: Memorializing in Social Media." Ethnologia Fennica 42 (2015): 7-22.

Haynes, Renée. 1980. “The Boggle Threshold.” Encounter, no. August 1980 (August): 92-96.

Healy, Michael John, and Michael B. Beverland. 2013. "Unleashing the Animal within: Exploring Consumers' Zoomorphic Identity Motives." Journal of Marketing Management 29 (1-2): 225-48. https: / / doi.org/10.1080/0267257X.2013.766233.

Jasanoff, Sheila. 2004. States of Knowledge: The Co-Production of Science and the Social Order. London/New York: Routledge. https: / / doi.org/10.4324/9780203413845. 
Johnston, Jay. 2013. “On Having a Furry Soul: Transpecies Identity and Ontological Indeterminacy in Otherkin Subcultures." In Animal Death, edited by Fiona ProbynRapsey and Jay Johnston, 293-306. Sydney, New South Wales: Sydney University Press.

—_. 2014. "Vampirism, Lycanthropy, and Otherkin." In The Occult World, edited by Christopher Partridge, 412-23. New York: Routledge.

Kirby, Danielle. 2008. "Alternative Worlds: Metaphysical Questioning and Virtual Community Amongst the Otherkin." In Through a Glass Darkly: Reflections on the Sacred: Sydney Studies in Religion, 275-287. Sydney, New South Wales: Sydney University Press.

—_. 2013. Fantasy and Belief: Fiction and Media as Conjunct Locales for Metaphysical Questing and Spiritual Understanding. Sheffield, UK: Equinox Publishing.

Knorr-Cetina, Karin. 1999. Epistemic Cultures: How the Sciences Make Knowledge. Cambridge, MA: Harvard University Press.

Latour, Bruno. 1988. Science in Action: How to Follow Scientists and Engineers Through Society. Cambridge, MA: Harvard University Press.

Laycock, Joseph. 2009. Vampires Today: The Truth about Modern Vampirism. Westport, CT: Praeger.

— 2010. "Real Vampires as an Identity Group: Analyzing Causes and Effects of an Introspective Survey by the Vampire Community." Nova Religio: The Journal of Alternative and Emergent Religions 14 (1): 4-23. https:/ / doi.org/10.1525/nr.2010.14.1.4.

—_ 2012. "'We Are Spirits of Another Sort': Ontological Rebellion and Religious Dimensions of the Otherkin Community." Nova Religio: The Journal of Alternative and Emergent Religions 15: 65-90. https:/ / doi.org/10.1525/nr.2012.15.3.65.

Lingel, Jessa. 2017. Digital Countercultures and the Struggle for Community. MIT Press. http:/ / www.jstor.org/stable/j.ctt1nxqpsm.

Luhrmann, T. M. 2014. "Opinion I Where Reason Ends and Faith Begins." The New York Times, July 26, 2014, sec. Opinion. https: / / www.nytimes.com/2014/07/27/opinion/sunday/tm-luhrmann-where-reason-ends-and-faith-begins.html.

Lupa. 2007. A Field Guide to Otherkin. Stafford, UK: Megalithica Books; 1st edition.

Lynch, Michael. 2017. "STS, Symmetry and Post-Truth." Social Studies of Science 47 (4): 593-99. https: / / doi.org/10.1177/0306312717720308.

Melzack, Ronald. 1989. "Phantom Limbs, the Self and the Brain." Canadian Psychology/Psychologie Canadienne 30 (1): 1-16. https: / / doi.org/10.1037/ h0079793.

Merton, Robert K. 1973. Sociology of Science: Theoretical and Empirical Investigations. Chicago: University of Chicago Press.

Miller, Daniel. 2017. "The Ideology of Friendship in the Era of Facebook." HAU: Journal of Ethnographic Theory 7 (1): 377-95. https: / / doi.org/10.14318/hau7.1.025.

Miller, Daniel, and Jolynna Sinanan. 2017. Visualising Facebook: A Comparative Perspective. UCL Press.

Nelson, Alondra. 2008. "Bio Science: Genetic Genealogy Testing and the Pursuit of African Ancestry." Social Studies of Science 38 (5): 759-83. https: / / doi.org/10.1177/0306312708091929. 
2016. The Social Life of DNA: Race, Reparations, and Reconciliation After the Genome. 1 edition. Beacon Press.

Nightside, Amelia. 2015. "Common Terminology."

Nota, Nienke M., Baudewijntje P. C. Kreukels, Martin den Heijer, Dick J. Veltman, Peggy T. Cohen-Kettenis, Sarah M. Burke, and Julie Bakker. 2017. "Brain Functional Connectivity Patterns in Children and Adolescents with Gender Dysphoria: Sex-Atypical or Not?" $\begin{array}{llll}\text { Psychoneuroendocrinology } & 86 & \text { (December): } & \text { 187-95. }\end{array}$ https: / / doi.org/10.1016/j.psyneuen.2017.09.014.

NurMuhammad, Rizwangul, Heather A. Horst, Evangelia Popoutsaki, and Giles Dodson. 2016. "Uyghur Transnational Identity on Facebook: On the Development of a Young Diaspora." Identities: Global Studies in Culture and Power 23 (4): 485-99. https: / / doi.org/10.1080/1070289X.2015.1024126.

O'Callaghan, Sean. 2015. "Navigating the 'Other' World: Cyberspace, Popular Culture and the Realm of the Otherkin." Culture and Religion 16 (3): 253-68. https: / / doi.org/10.1080/14755610.2015.1083454.

Panofsky, Aaron, and Joan Donovan. 2017. "When Genetics Challenges a Racist's Identity: Genetic Ancestry Testing among White Nationalists." In . https: / / doi.org/10.31235/osf.io/7f9bc.

Pew Research Center. 2018. "Social Media Fact Sheet." Pew Research Center: Internet, Science \& Tech (blog). February 5, 2018. http: / / www.pewinternet.org/ fact-sheet/ social-media/.

Phillip, Abby. 2015. “Online 'Authenticity' and How Facebook's 'Real Name' Policy Hurts Native Americans." Washington Post, February 10, 2015. https: / / www.washingtonpost.com/news/morning-mix/wp/2015/02/10/onlineauthenticity-and-how-facebooks-real-name-policy-hurts-native-americans /.

Phillips, Whitney. 2015. This Is Why We Can't Have Nice Things: Mapping the Relationship Between Online Trolling and Mainstream Culture. MIT Press.

Phillips, Whitney, and Ryan M. Milner. 2017. The Ambivalent Internet: Mischief, Oddity, and Antagonism Online. 1 edition. Cambridge, UK; Malden, MA: Polity.

Probyn-Rapsey, Fiona. 2011. "Furries and the Limits of Species Identity Disorder: A Response to Gerbasi et Al." Society $\mathcal{E}$ Animals 19: 294-301. https: / / doi.org/10.1163/156853011X578956.

Proctor, Devin. 2018. "Cybernetic Animism: Non-Human Personhood and the Internet." In Digital Existence: Ontology, Ethics and Transcendence in Digital Culture, edited by Amanda Lagerkvist, 227-41. New York: Routledge.

Reardon, Jenny. 2004. Race to the Finish: Identity and Governance in an Age of Genomics. Princeton: Princeton University Press.

Reardon, Jenny, and Kim TallBear. 2012. "'Your DNA Is Our History': Genomics, Anthropology, and the Construction of Whiteness as Property." Current Anthropology 53 (S5): S233-45. https: / / doi.org/10.1086/662629. 
Roberts, Sharon, Courtney. Plante, Kathleen Gerbasi, and Stephen Reysen. 2015. "The Anthrozoomorphic Identity: Furry Fandom Members' Connections to Nonhuman Animals." Anthrozoös 28 (4): 533-48. https:/ / doi.org/10.1080/08927936.2015.1069993.

Robertson, Venetia Laura Delano. 2012. "The Law of the Jungle: Self and Community in the Online Therianthropy Movement." Pomegranate: The International Journal of Pagan Studies 14 (2): 256-80.

—_ 2013. "The Beast Within: Anthrozoomorphic Identity and Alternative Spirituality in the Online Therianthropy Movement." Nova Religio: The Journal of Alternative and Emergent Religions 16 (3): 7-30. https:/ / doi.org/10.1525/nr.2013.16.3.7.

Scribner, Orion. 2012. Otherkin Timeline: The Recent History of Elfin, Fae, and Animal People. Creative Commons License. http: / / orion.kitsunet.net.

Senter, Philip J., and Jared J. Mackey. 2017. "The Evolution of Creation Science, Part 1: Vestigial Structures and Biological Degeneration." Perspectives on Science and Christian Faith 69 (1): 27-27.

Shane, Margaret. 2014. “Some People Aren't People on the Inside." In Educational, Psychological, and Behavioral Considerations in Niche Online Communities, edited by Vivek Venkatesh, 260-71. Hershey, PA: Information Science Reference. https://doi.org/10.4018/978-14666-5206-4.ch016.

Shapin, Steven, and Simon Schaffer. 1985. Leviathan and the Air-Pump: Hobbes, Boyle, and the Experimental Life. Princeton, N.J: Princeton University Press.

Sismondo, Sergio. 2017a. "Post-Truth?" Social Studies of Science 47 (1): 3-6. https: / / doi.org/10.1177/0306312717692076.

—— 2017b. "Casting a Wider Net: A Reply to Collins, Evans and Weinel." Social Studies of Science 47 (4): 587-92. https: / / doi.org/10.1177/0306312717721410.

Snook, Jennifer. 2015. American Heathens: The Politics of Identity in a Pagan Religious Movement. Temple University Press.

Star, Susan Leigh, and James R. Griesemer. 1989. “Institutional Ecology, 'Translations' and Boundary Objects: Amateurs and Professionals in Berkeley's Museum of Vertebrate Zoology, 1907-39." Social Studies of Science 19 (3): 387-420. https: / / doi.org/10.1177/030631289019003001.

Stefano, Jason de. 2015. "From Objectivity to the Scientific Self: A Conversation with Peter Galison." Qui Parle 23 (2): 89-114. https: / / doi.org/10.5250/ quiparle.23.2.0089.

TallBear, Kim. 2013. Native American DNA: Tribal Belonging and the False Promise of Genetic Science. Minneapolis, MN: Univ Of Minnesota Press.

The Otherkin Community, Inc. 2016. "The Otherkin Community: Home." The Otherkin Community. Accessed July 26, 2018. https:/ / www.otherkincommunity.net.

Thompson, Charis. 2007. Making Parents: The Ontological Choreography of Reproductive Technologies. Edited by Wiebe E. Bijker, W. Bernard Carlson, and Trevor Pinch. 1 edition. Cambridge, Mass.: The MIT Press.

Toumey, Christopher P. 1991. "Modern Creationism and Scientific Authority." Social Studies of Science 21 (4): 681-99. https: / / doi.org/10.1177/ 030631291021004003. 
Williams, D. J. 2008. "Contemporary Vampires and (Blood-red) Leisure: Should We Be Afraid of the Dark?" Leisure/Loisir 32 (2): 513-39.

. 2009. "Deviant Leisure: Rethinking 'The Good, the Bad, and the Ugly.'” Leisure Sciences 31 (2): 207-13. https:/ / doi.org/10.1080/01490400802686110. 